\title{
Design and Fabrication of Rice De-Stoning Machine
}

\author{
Olugboji Oluwafemi Ayodeji., Jiya Jonathan Yisa. * \\ Mechanical Engineering Department, Federal University of Technology, Minna Niger State. Nigeria \\ *Corresponding Author: jojileg@yahoo.com
}

Copyright $@ 2014$ Horizon Research Publishing All rights reserved.

\begin{abstract}
This work aims at meeting the ever increasing demands of quality rice, avoiding losses and improving the income of local farmers. Mild steel was used in the construction of the machine. Standard equations were used to determine the dimension of the parts. The machine is driven by a $1 \mathrm{Hp}$ electric motor with $688.17 \mathrm{~W}$ required power. The machine has a capacity of $47.39 \mathrm{Kg} / \mathrm{hr}$ and an efficiency of $82.47 \%$
\end{abstract}

Keywords De-Stoning, Separator, Feed Material, Exciter, Sieve

\section{Introduction}

Rice is a popular tropical cereal considered to be an important food item. This because it supplies a quarter of the entire calorific intake of human race as stated by Babatunde (2004).

F. A. O. (1995) gave statistics which shows that rice is a staple food of well over $90 \%$ of the world's population. This means rice has been of very great economic importance.

Therefore, availability of processing machines becomes an important essential aspect of agro-allied industries. In Nigeria most of the agro-allied products are consumed or exported unprocessed, this has negative effects on the economy of our nation. The separation of grains from stone and other impurities before consumption or further processing into various products is one step that is necessary in improving agro-allied industries. This step will ensure the quality and hygiene of products, thus increasing the commercial value of the final exported or consumed products.

Also, with the current increase observed in our local production of rice in Nigeria, owing largely to the present policy of government on imported items, there is need to give attention and organisation to agro-allied industries and their products.

This work therefore aims at producing Rice de-stoning machine with vibrating screens on two stages using simplified exciters. With the development of the machine for processing of rice, demand for our locally produced rice will increase with its attendant gains on the economy.

\section{Theoretical Analysis}

Rice de-stoning machine is made up of two sets of carriage each comprising of three screens. The first in each working deck serves to separate the stones slightly bigger than the grain; the second screen serves to separate the stones smaller in size than the grains while the third screen serves to convey the stones down to the stone chutes. The screens one and two are special wire gauze designed for separation purposes. The two working decks are designed to be slanted in opposing angles of between $7^{\circ}$ to $14^{\circ}$ to the horizontal. The angle can be varied in relation to the speed and efficiency required. The two decks are held in position by four flexible suspension reeds by means of belts and nuts on the upper part of the machine frame.

The two decks are connected together and are mounted on the frame work which connects them to the shaft rotating. The shaft has two exciters on which are meant to excite the system, the offset angle can be arranged to obtain high or low vibration. Also, on the shaft are two bearings giving support to the shaft and pulley which receives drive from an electric motor via a belt.

The hopper is fixed on the upper frame to receive charge for the first deck. Rough rice (rice with impurities) when charged through the hopper, gradually passes through the throat of the hopper and falls on the first screen with angle of inclination $7^{\circ}$ to $14^{\circ}$ as convenient and effective. The rate of floe from hopper is controlled manually.

By this time, the prime mover drives the shaft carrying the exciters, thus the whole working deck is vibrated. As the working deck is vibrated, the rough rice is caused to move on the first screen thereby the bigger stone and impurities move down while smaller materials including rice dropped off on the second screen. Now the cleaner rice falls on the second working deck where the process is repeated. The second working deck will improve on the efficiency of the first separation. There are two outlets, the first, to collect the impurities and the second to collect the clean rice. 


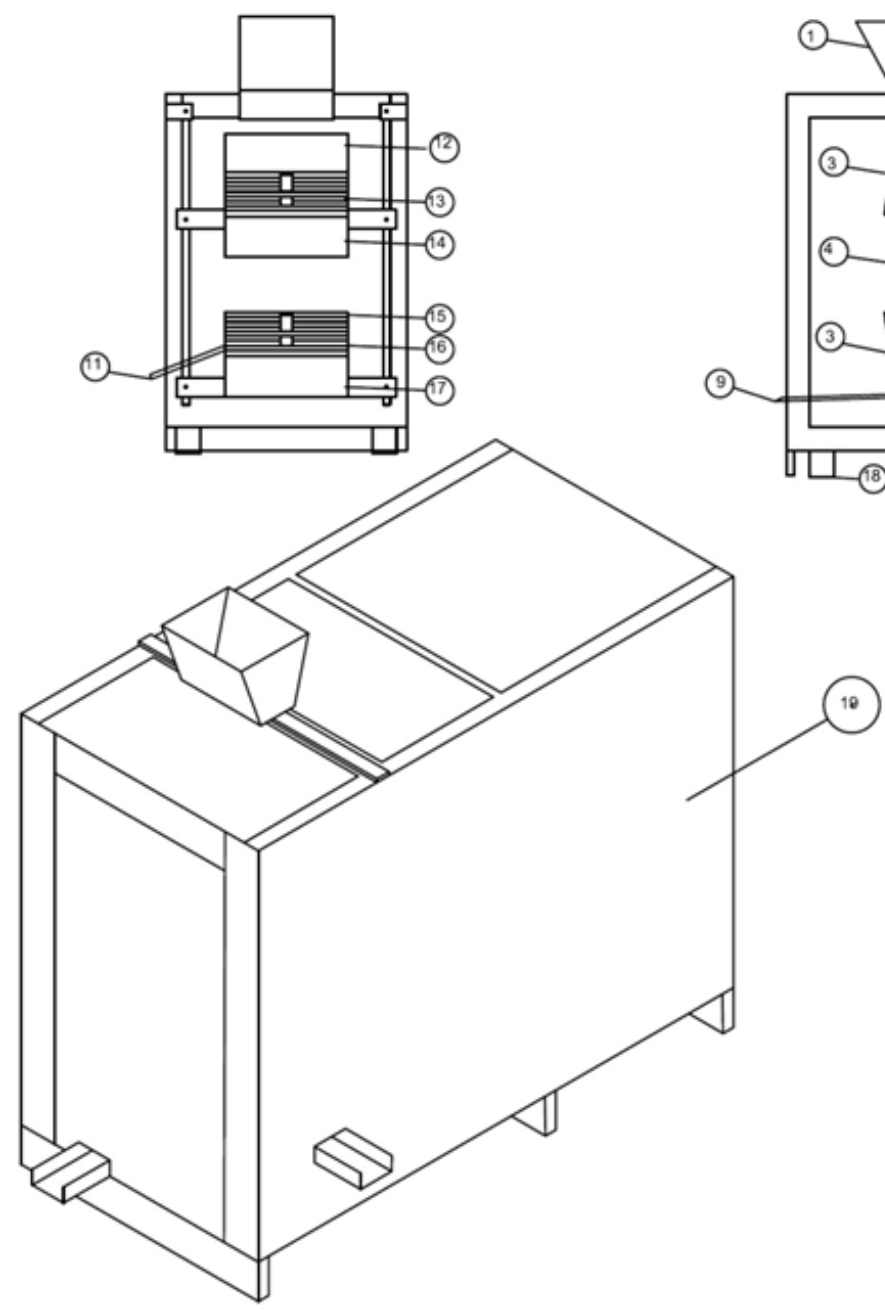

\begin{tabular}{|c|c|c|c|}
\hline 19. & PAOTECTIVECOVERS & & MS SHEET METAL \\
\hline 18. & DAMPER & 4 & RUPBER \\
\hline 17. & SCREEN 3, LOWER DECK & 1 & M.S SHEET METAL \\
\hline 16. & SCREEN 2, LOWER DECK & 1 & WRECLOTHMS \\
\hline 15. & SCREEN 1, LOWER DECK & 1 & WRECLOTHMS \\
\hline 14. & SCREEN 3, UPPER DECK & 1 & MS SHEET METAL \\
\hline 13. & SCREEN 2 , UPPER DECK & 1 & WRECLOTHSMS \\
\hline 12. & SCREEN 1, UPPER DECK & 1 & WIRE CLOTHMS \\
\hline 11. & SEECTED MATERLALOUTLET & 1 & SHEETMETALMS \\
\hline 10. & EXCITERFRAME & 1 & ANGLF BARMS \\
\hline 9 & FOAEIGN MATTER OUTLET & 1 & SHEET METALMS \\
\hline 8 & EXCITER & 2 & M.S \\
\hline 7. & DEVEN PULLEY & 1 & AUMMINIUM \\
\hline 6 & SEECTED MATERLALCHUTE & 1 & METAL SHEET MS \\
\hline 5 & FOREIGN MATTERCHUTE & 2 & METAL SHEET MS \\
\hline 4 & SUSPENSION REEOS & 4 & FLAT BAR MS \\
\hline$\overline{3}$ & WOAXING DECIS & 2 & ANGLF BARMS \\
\hline 2 & MATERLAL INLET SUPPOAT & 2 & FLAT BAR MS \\
\hline 1 & MATERLAL INLET & 1 & MLOSTEE. SHEET \\
\hline S/NO & DESCRIPTION & $Q \pi /$ & MATERLAL \\
\hline \multicolumn{4}{|c|}{ PARTS UST } \\
\hline
\end{tabular}

Figure 1. Rice de-stoning machine

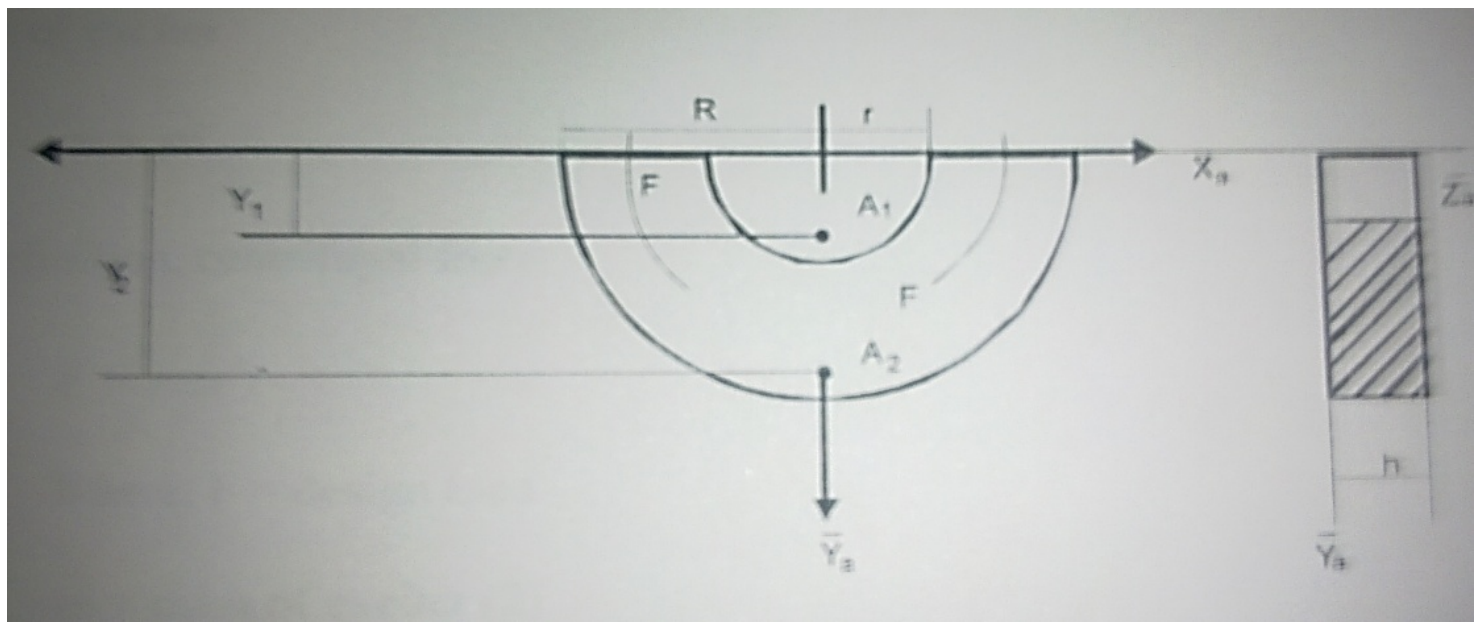

Figure 2. Determination of Exciter disc dimensions

\section{Design Analysis}

Determination of Exciter Disc Dimension, Speed of rotation and Power required to drive sieve.

The assumption: the centrifugal force generated by the two exciters produces the longitudinal action of the working decks. From Figure 2, the volume of the inner circle (hole) is given by (Charles, 1989) 


$$
\mathrm{V}_{1}=\frac{\pi \mathrm{r}^{2}}{2} \mathrm{~h}
$$

The radius of gyration is given by,

$$
\mathrm{Y}_{1}=\frac{4 \mathrm{r}}{3 \pi}
$$

Also, the volume of outer circle (solid) is given as,

$$
\mathrm{V}_{2}=\frac{\pi \mathrm{Rh}}{2}
$$

The radius of gyration is given as,

$$
\mathrm{Y}_{2}=\frac{4 \mathrm{r}}{3 \pi}
$$

Effective radius of gyration

$$
\overline{\mathrm{Y}}=\frac{\sum \mathrm{VY}}{\sum \mathrm{V}}=\frac{\mathrm{V}_{2} \mathrm{Y}_{2}-\mathrm{V}_{1} \mathrm{Y}_{1}}{\mathrm{~V}_{2}-\mathrm{V}_{1}}
$$

Effective volume of Revolution

Mass of Exciter

$$
\mathrm{V}=\mathrm{V}_{2}-\mathrm{V}_{1}
$$

By definition, centrifugal force

$$
\mathrm{M}=\rho \mathrm{V}
$$

Where, $\mathrm{F}=$ design load

$$
\mathrm{F}=\mathrm{m} \omega^{2} \mathrm{r}
$$

$\mathrm{m}=$ mass of Exciter

$\mathrm{r}=$ radius of gyration

$\omega=$ angular speed of rotation in radians

Therefore speed of the Exciter required is

$$
\omega=\sqrt{\frac{F}{2 m r}}
$$

Converting to revolutions per minute

$$
\mathrm{N}=\frac{\omega 60}{2 \pi}
$$

Torque generated, according to Jonnes (1995)

$\mathrm{T}=\mathrm{Fr}$

Where, $\mathrm{F}=$ design load

$\mathrm{r}=$ radius of gyration

Hence, power required to drive sieve;

$\mathrm{P}=\mathrm{T} \omega$

\section{Power Transmission and Belt Tension}

Torque transmitted to pulley according to Rober and Moth (1982), is given by

And,

$$
\mathrm{M}_{1}=\frac{9550(\mathrm{~kW})}{\mathrm{N}(\mathrm{rpm})}
$$

$\mathrm{T}_{1}=\left(\mathrm{T}_{1}-\mathrm{T}_{2}\right) \mathrm{R}(\mathrm{Nm})$

In a vee-grooved pulley belt drive, the relationship between $\mathrm{T}_{1}$ and $\mathrm{T}_{2}$ is given by

$$
\frac{\mathrm{T}_{1}}{\mathrm{~T}_{2}}=\mathrm{e}^{\mu \theta \operatorname{cosec} \frac{\phi}{2}}
$$

Where, $\mathrm{T}_{1}=$ tension on tight side of belt

$$
\begin{aligned}
& \mathrm{T}_{2}=\text { tension on slack side of belt } \\
& \mu=\text { coefficient of friction } \\
& \theta=\text { groove angle of pulley } \\
& \phi=\text { angle of lapped by belt on pulley }
\end{aligned}
$$

From Figure 2, the angle of wrap of an open belt pulley may be determined by,

$\theta_{1}=180-2 \beta$ $\theta_{2}=180+2 \beta$

$\beta=\sin ^{-2}\left(\frac{\mathrm{R}-\mathrm{r}}{\mathrm{c}}\right)$

According to Hannah and Hillier (1978), velocity ratio relationship of belt drive power transmission is given as

$\mathrm{N}_{1} \mathrm{D}_{1}=\mathrm{N}_{2} \mathrm{D}_{2}$

\section{Determination of Shaft Size}

Noting that the shaft is subjected to combined torsional and bending moments, then based on maximum shear stress theory, the maximum shear stress;

Where,

$$
\left.\sigma_{\max }=\frac{1}{2} \sqrt{\left(\sigma_{\mathrm{b}}^{2}\right.}+4 \sigma_{\mathrm{t}}^{2}\right)
$$

$\sigma_{\mathrm{b}}=$ bending stress

$\sigma_{\mathrm{t}}=$ torsional stress

According to Ryder (1988)

$$
\begin{gathered}
\sigma_{\mathrm{b}}=\frac{32 \mathrm{M}}{\pi \mathrm{d}^{3}} \\
\sigma_{\mathrm{t}}=\frac{16 \mathrm{~T}}{\pi \mathrm{d}^{3}}
\end{gathered}
$$

Substituting into equation

$$
\begin{gathered}
\sigma_{\max }=\frac{1}{2} \sqrt{\left\{\left(\frac{32 \mathrm{M}}{\pi \mathrm{d}^{3}}\right)^{2}+4\left(\frac{16 \mathrm{~T}}{\pi \mathrm{d}^{3}}\right)^{2}\right\}} \\
=\frac{16}{\pi \mathrm{d}^{3}} \sqrt{\left(\mathrm{M}^{2}+\mathrm{T}^{2}\right)} \\
=\frac{16}{\pi \mathrm{d}^{3}} \sqrt{\left(\mathrm{MK}_{\mathrm{b}}\right)^{2}+\left(\mathrm{TK}_{\mathrm{t}}\right)^{2}} \\
\mathrm{~d}^{3}=\frac{16}{\pi \sigma_{\max }} \sqrt{\left(\mathrm{MK}_{\mathrm{b}}\right)^{2}+\left(\mathrm{TK}_{\mathrm{t}}\right)^{2}}
\end{gathered}
$$

Where,

$\mathrm{K}_{\mathrm{b}}=$ combine shock and fatigue factor for bending

$\mathrm{K}_{\mathrm{t}}=$ combine shock and fatigue factor for torsion

\section{Determination of Bearing Size for Shaft Support}

For a shaft rotating at constant speed, we have

$$
\mathrm{L}_{\mathrm{io}}=\frac{10^{6}}{60 \mathrm{n}}\left(\frac{\mathrm{c}}{\mathrm{p}}\right)^{\mathrm{q}}
$$

Where,

$\mathrm{L}_{\mathrm{io}}=$ basic rating life in hours

$\mathrm{c}=$ basic dynamic load rating

$\mathrm{p}=$ equivalent dynamic bearing load

$\mathrm{q}=$ exponential life of equation

$\mathrm{n}=$ angular speed of shaft in revolutions per minute (rpm)

Hence,

$$
\mathrm{c}=\mathrm{p}\left(\frac{\mathrm{L}_{\mathrm{i} 0} 60 \mathrm{n}}{10^{6}}\right)^{\frac{1}{9}}
$$

When $\mathrm{c}$ is determined, the bearing is then selected from tables

\section{Determination of Sieve Suspension Reed (Hanger) Dimensions}

Since there are four hangers (suspension reeds) carrying the sieving unit, we obtain load per support as; 


$$
\mathrm{F}_{\mathrm{sl}}=\frac{\mathrm{F}_{\mathrm{D}}}{4}
$$

Where,

$\mathrm{F}=$ design load

Bending moment due to drive mechanism

$$
\mathrm{M}_{\mathrm{b}}=\mathrm{F}_{\mathrm{sl}} \mathrm{l}
$$

Where,

$1=$ distance from upper frame to the lower connection of the working deck.

According to Franklin and Joseph (1981), the yield strength of a material is

$$
\sigma_{\mathrm{y}}=\frac{\mathrm{M}_{\mathrm{b}}}{\mathrm{Z}}
$$

and,

$$
Z=\frac{b d^{3}}{6}
$$

Also, by definition, deflection of simple beam,

$$
\delta_{\max }=\frac{\mathrm{F}_{\mathrm{sl}} \mathrm{l}^{3}}{3 \mathrm{EI}}
$$

Where,

$$
\begin{aligned}
& \mathrm{F}_{\mathrm{sl}}=\text { load per support } \\
& \mathrm{E}=\text { modulus of elasticity } \\
& \mathrm{I}=\text { moment of inertia }
\end{aligned}
$$

$$
\mathrm{I}=\frac{\mathrm{bd}^{3}}{12}
$$

Hence, stiffness $\mathrm{k}$ of each bar is

$$
\mathrm{k}=\frac{\mathrm{F}_{\mathrm{sl}}}{\delta_{\max }}
$$

For the four bars, total stiffness is

$$
\mathrm{k}_{\mathrm{T}}=4 \frac{\mathrm{F}_{\mathrm{sl}}}{\delta_{\max }}
$$

Determination of Amplitude and Frequency of Vibration

According to Anderson (1987), for a system of force vibration with single degree of freedom, the amplitude;

$$
Y=\frac{F / k}{\left[\left\{1-\left(\frac{\omega}{\omega_{n}}\right)^{2}\right\}^{2}+\left\{2 \xi\left(\frac{\omega}{\omega_{n}}\right)\right\}^{2}\right]^{0.5}}
$$

Where,

$\mathrm{F}=$ magnitude of excitation force

$\mathrm{k}=$ stiffness of spring (suspension reeds)

$\mathrm{Y}=$ amplitude of steady state vibration

$\mathrm{m}=$ mass of system

$\xi=$ coefficient of damping

$\omega=$ frequency of excitation force, given by

$\omega=\frac{2 \pi N}{60}$

$\omega_{\mathrm{n}}=$ natural frequency of vibration of the system, given by,

$$
\omega_{\mathrm{n}}=\sqrt{\frac{k}{m}}
$$

Frequency of vibration, $f$ of the system is therefore,

$$
f=\frac{\omega}{2 \pi}
$$

\section{Design for Bolted Connection}

The exciter is connected to the working decks by a frame with four bolts.

The load per each bolt is $F_{b}$

$$
\mathrm{F}_{\mathrm{b}}=\frac{F}{4}
$$

Where,

$\mathrm{F}$ is design load

To take care of impact load due to sieving, an impact factor of 2 is chosen

$$
\mathrm{F}_{\mathrm{b}}=\frac{F}{2}
$$

Since the pre-stressing diagram cannot be drawn due to lack of bolt, we use the following (Gitin and Parad)

$$
\mathrm{F}_{\max }=1.5 \mathrm{~F}_{\mathrm{bs}}
$$

Using a bolt material property class of 4.8 we obtain the material yield stress $\mathrm{T}_{\mathrm{y}}=340 \mathrm{MPa}$ (Shigley and Mischke, 2001).

Hence, the design stress

$$
\mathrm{T}_{\mathrm{P}}=0.3 \mathrm{~T}_{\mathrm{y}}
$$

And the required bolt core area

$$
\mathrm{A}_{\mathrm{c}}=\frac{F_{\max }}{T_{p}}
$$

But,

$$
\begin{aligned}
& \mathrm{A}_{\mathrm{c}}=\frac{\pi d^{2}}{4} \\
& \mathrm{~d}=\sqrt{\frac{4 A_{c}}{\pi}}
\end{aligned}
$$

\section{Material Selection}

The particular conditions under which the various parts of the Rice de-stoning machine are subjected to, makes it necessary to select adequate materials for the fabrication based on functionality, durability, ability to withstand vibration and the cost of such materials. In the choice of material, their physical properties and behaviour are considered such that when subjected to the machine running condition should be able to withstand the service condition.

In this design, the strength of the materials, serviceability of parts and availability were put into consideration. This led to the selection of mild steel angle bar $(40 \mathrm{x} 40 \mathrm{~mm})$ for the frame, mild steel angle bar $(25 \times 25 \mathrm{~mm})$ for the working decks and gauge 24 mild steel sheets for the protective guards and hopper. For the pulley, aluminum was selected for light eight and mild steel plates selected for the exciter disc. Also, painting of the machine was carried out for aesthetic aspect and to prevent rusting of parts. 
Table 1. Result of Test Analysis

\begin{tabular}{ccccccc}
\hline S/No. & $\begin{array}{c}\text { Clean Rice } \\
\text { sample }(\mathrm{kg})\end{array}$ & $\begin{array}{c}\text { Stones sample } \\
(\mathrm{kg})\end{array}$ & $\begin{array}{c}\text { Feed materials } \\
(\mathrm{kg})\end{array}$ & $\begin{array}{c}\text { Clean Grain } \\
\text { Outlet }(\mathrm{kg})\end{array}$ & $\begin{array}{c}\text { Foreign matter } \\
\text { outlet }(\mathrm{kg})\end{array}$ & $\begin{array}{c}\text { Time taken } \\
(\mathrm{min})\end{array}$ \\
\hline 1 & 3.0 & 0.25 & 3.25 & 2.59 & 0.66 & 4.0 \\
2 & 2.5 & 0.2 & 2.70 & 2.27 & 0.43 & 3.5 \\
3 & 3.0 & 0.3 & 3.30 & 2.76 & 0.54 & 4.2 \\
\hline
\end{tabular}

Therefore, de-stoning efficiency is taken as

$$
\begin{gathered}
S=\frac{\text { massofgrain obtained at clean grain outlet }}{\text { total mass of feed material }} \\
\times 100
\end{gathered}
$$

Hence, from Table 1 above,

$$
\begin{aligned}
\int_{\zeta 1} & =\frac{2.59}{3.25} \times 100=79.69 \% \\
\zeta \int_{2} & =\frac{2.27}{2.70} \times 100=84.07 \% \\
\int_{\zeta 3} & =\frac{2.76}{3.30} \times 100=83.64 \%
\end{aligned}
$$

Average efficiency $=\frac{\{1+\zeta\{+\zeta\{}{3}$

$$
\begin{gathered}
=\frac{79.67+84.07+83.64}{3} \\
=82.47 \%
\end{gathered}
$$

And, capacity of machine per hour is

$$
\begin{gathered}
C=\frac{60 X \text { Feed material }}{\text { Time taken }} \\
\mathrm{C}_{1}=48.75 \mathrm{~kg} / \mathrm{hr} \\
\mathrm{C}_{2}=46.28 \mathrm{~kg} / \mathrm{hr} \\
\mathrm{C}_{3}=47.14 \mathrm{~kg} / \mathrm{hr}
\end{gathered}
$$

Average capacity of the machine is

$$
C=\frac{48.75+46.28+47.14}{3}=47.39 \mathrm{~kg} / \mathrm{hr}
$$

\section{Conclusion}

The design and fabrication of a Rice Destoning Machine was successfully carried by this work with an efficiency of $82.47 \%$ attained. The machine was tested and found capable of de-stoning rice. Due to the low cost of fabrication the machine can be adopted by small scale producers.

\section{REFERENCES}

[1] Anderson J. S. and Bratos - Anderson M. (1987) Solving problems in vibrations,

[2] Longman Scientific and Technical ltd, England, pp. 69-74

[3] V. Konokhova (1985), Rice growing revised edition, Mir publisher Moscow. Pp. 9-12,154,166

[4] Franklin E.F. and Joseph H. Faupel (1981) Engineering Design (A synthesis of stress analysis and material engineering), 2nd Edition, Willey and sons' inc. pp.99-105, 1008

[5] Hannah J. and Hillier M.J. (1978) Mechanical Engineering Science, Pitman publishing Parker street, London, pp. 124-128

[6] Joseph E. Shigley and Charles R. Mishke (2001) Mechanical Engineering Design, 6th edition, McGraw Hill, New York, pp.469-558

[7] Rober L. and Moth P.E. (1982) Machine Elements and Mechanical Design 2nd edition, Macmillan Publishing company, New york. Pp. 598-614

[8] Babatunde T. (2004) Design and Construction of Motorized Rice Threshing Machine. Unpublished Undergraduate Thesis. Federal University of Technology, Minna. Nigeria.

[9] Charles C. (1989) Design and Construction of Multipurpose Mechanical Exciter and Vibratory Conveyor. Unpublished Undergraduate Thesis. Federal University of Technology, Minna. Nigeria.

[10] Rober L. and Moth P. E. (1982) Machine Elements and Mechanical Design. Second Edition, Macmillan Publishing Company, New York. Pp 598-614.

[11] Hannah J. and Hillier M. J (1978) Mechanical Engineering Science, Pitman Publishing Parker Street, London. Pp 124 128.

[12] Ryder G. H. (1988) Strength of Materials 3rd Edition. Macmillan Publishing Company, New York.

[13] Franklin E. F and Joseph H. F (1981) Engineering Design ( A synthesis of stress analysis and material engineering) Second Edition, Willey and Son's Incorporation, pp 99 - 105, $999-1008$. 